\title{
BMJ Open Utilisation of immediate postpartum family planning among postpartum women at public hospitals of North Shoa Zone, Ethiopia: a cross- sectional study
}

\author{
Mulualem Silesh (D) , ${ }^{1}$ Tesfanesh Lemma (D) , ${ }^{1}$ Samuel Abdu, ${ }^{2}$ Belete Fenta, ${ }^{3}$ \\ Mesfin Tadese (D) , ${ }^{1}$ Birhan Tsegaw Taye
}

To cite: Silesh M, Lemma T, Abdu S, et al. Utilisation of immediate postpartum family planning among postpartum women at public hospitals of North Shoa Zone, Ethiopia: a cross-sectional study. BMJ Open 2022;12:e051152. doi:10.1136/ bmjopen-2021-051152

- Prepublication history for this paper is available online. To view these files, please visit the journal online (http://dx.doi. org/10.1136/bmjopen-2021051152).

Received 13 March 2021 Accepted 26 January 2022

A) Check for updates

(C) Author(s) (or their employer(s)) 2022. Re-use permitted under CC BY-NC. No commercial re-use. See rights and permissions. Published by BMJ.

${ }^{1}$ School of Nursing and Midwifery, Asrat Woldeyes Health Science Campus, Debre Berhan University, Debre Berhan, Ethiopia

${ }^{2}$ School of Nursing, Institute of health, Jimma University, Jimma, Ethiopia

${ }^{3}$ School of Midwifery, Institute of health, Jimma University, Jimma, Ethiopia

Correspondence to

Mr Mulualem Silesh;

sileshmulualem22@gmail.com

\section{ABSTRACT}

Objective This study aimed to assess the prevalence of immediate postpartum family planning utilisation and the associated factors among postpartum women at public hospitals of North Shoa Zone, Ethiopia.

Design and methods A facility-based cross-sectional study was conducted in 1-30 May 2020. Systematic random sampling technique was used to select the participants. Data were collected through a face-to-face interview using a structured and pretested questionnaire. Univariate and multivariable logistic regression analyses were employed. In multivariable logistic regression analysis, $p<0.05$ and adjusted OR (AOR) with $95 \% \mathrm{Cl}$ were used to declare statistically significant factors.

Setting and participants The study was conducted at public hospitals of North Shoa Zone, Ethiopia. A total of 394 postpartum women within 48 hours after giving birth before discharge from the selected hospitals were enrolled in the study.

Outcome Immediate postpartum family planning utilisation (used or not used).

Results Of the total 394 participants, 84 (21.3\%) used immediate postpartum family planning. The factors associated with immediate postpartum family planning utilisation were women's age (30-34 years) (AOR: 0.118; $95 \% \mathrm{Cl} 0.023$ to 0.616 ), planning status of pregnancy (A0R: 3.175; 95\% Cl 1.063 to 9.484), reproductive intention (AOR: $5.046 ; 95 \% \mathrm{Cl} 1.545$ to 16.479 ), partner support (AOR: $4.293 ; 95 \% \mathrm{Cl} 1.181$ to 15.61 ), attitude towards family planning (AOR: $2.908 ; 95 \% \mathrm{Cl} 1.081$ to 7.824) and maternal satisfaction with intrapartum care (AOR: 6.243; 95\% Cl 2.166 to 17.994).

Conclusion In the study area, only less than a quarter of postpartum women used immediate postpartum family planning. Therefore, enhancing immediate postpartum family planning utilisation, strengthening community awareness to develop a favourable attitude towards family planning, promoting partner involvement in family planning and ensuring maternal satisfaction during intrapartum care are essential.

\section{INTRODUCTION}

Access to contraceptive services through the integration of postpartum family planning

\section{Strengths and limitations of this study}

- To our knowledge, this is the first study to determine the utilisation of immediate postpartum family planning and the associated factors in northeast Ethiopia.

- All immediate postpartum family planning options were addressed according to the 2015 medical eligibility criteria for contraceptives.

- The study assessed maternal satisfaction with intrapartum care as a predictor of immediate postpartum family planning utilisation.

- As a cross-sectional design was used, the study does not establish a causal relationship between the outcome variable and the predictors.

- This study did not address service provider-related and healthcare system-related factors.

(PPFP) at times when women have frequent health-care visits, such as antenatal care (ANC), labor and delivery (L\&D), postnatal care (PNC), immunization, and child care, helps to reduce maternal and newborn mortality, as well as improve social and economic well-being. ${ }^{1-3}$

The postpartum period is a critical time to address the high unmet need for FP and reduce the risk of short interpregnancies. ${ }^{2}$ Immediate postpartum family planning (IPPFP) refers to the provision of FP counselling and services as part of care to postpartum women within 48 hours after childbirth before discharge from the health facility. ${ }^{45}$ Increasing the accessibility of contraception methods among postpartum women is an important strategy because women may initiate sexual activity before obtaining FP methods at their 6-week postpartum visit. ${ }^{6} 7$

According to the WHO 2015 medical eligibility criteria (MEC) for contraceptive 
use (fifth edition), postpartum women have a variety of options for FP during the immediate postpartum period. They can safely use contraceptives such as progesteroneonly pills (category 2), injectables (for non-breastfeeding women only; category 1), implants (category 2), postpartum intrauterine contraceptive devices (PPIUCD; category 1) and permanent FP (bilateral tubal ligation; category: accept) ${ }^{8}$

Globally, approximately 810 deaths associated with pregnancy and childbirth are recorded daily and about $94 \%$ of these maternal deaths occur in low-income and middle-income countries. ${ }^{9}$ As the WHO recommended for better maternal and child health outcomes, postpartum women should wait for an interval of at least 2 years following a live birth before getting pregnant again. ${ }^{10}$ Among couples who spaced their pregnancies for at least 2 years apart from the previous birth, the risk of morbidity and mortality for both the mother and the baby is reduced. ${ }^{11}$ For instance, infant and under-5 child mortalities decrease by $10 \%$ and $21 \%$, respectively. ${ }^{12}$ The 2016 Ethiopia Demographic and Health Survey report stated that under-5 child mortality is dramatically higher among children born less than 2 years after a previous birth (114 deaths per 1000 live births) compared with children born 3 years after a previous birth (44 deaths per 1000 live births). ${ }^{13}$

The time of return of fertility after childbirth is variable and unpredictable; postpartum women can get pregnant before the return of their menstruation. ${ }^{14}$ Therefore, postpartum women have a high unmet need for FP compared with other women, which is the primary cause of unintended pregnancies and maternal mortality. ${ }^{15} 16$ The prevalence of unintended pregnancies is the most challenging issue within maternal and child health and women's reproductive health. ${ }^{1718}$

The Ethiopian government planned to increase the rate of use of contraceptives among married women of reproductive age to $55 \%$ and reduce the unmet need to $10 \%$ by $2020 .{ }^{19}$ However, among postpartum women who did not intend to have children soon, only $23.7 \%$ use modern $\mathrm{FP}^{20}$ and $22 \%$ of children were born less than 2 years after their siblings. ${ }^{13}$ The 2019 Ethiopia Mini Demographic and Health Survey also showed that only $41 \%$ of currently married women use modern FP methods. ${ }^{21}$ Furthermore, IPPFP services are not yet widely used in Ethiopia ${ }^{22}$ and only $9 \%$ of postpartum women use IPPFP. ${ }^{23}$

Due to FP services being commonly provided during postnatal follow-up visits, ${ }^{24}$ along with other combination factors such as shorter periods of exclusive breast feeding (EBF), early return of menstruation and early resumption of sexual intercourse,${ }^{25}$ postpartum women often end up with a closely spaced and unplanned pregnancy. ${ }^{26}$ This implies that it is difficult to rely on EBF as an FP method and to address FP by waiting until 6 weeks of the postpartum period. The provision of IPPFP after childbirth before women are discharged from the health facility is an excellent opportunity for postpartum mothers.
Furthermore, most of the studies conducted on postpartum FP focused on the extended postpartum period. To the best of our knowledge, studies on IPPFP utilisation, including in Ethiopia, are limited. In addition, studies have not investigated the role of satisfaction with intrapartum care and its immediate impact on service utilisation. Therefore, this study aimed to assess the prevalence of IPPFP utilisation and the associated factors among postpartum women at public hospitals of North Shoa Zone, Ethiopia.

\section{Research questions}

- What is the prevalence of IPPFP utilisation?

- What are the factors associated with IPPFP utilisation?

\section{METHODS AND MATERIALS}

\section{Study design, period and setting}

A facility-based cross-sectional study was conducted at public hospitals of North Shoa Zone, Amhara Region in 1-30 May 2020. North Shoa Zone is one of 10 zones in Amhara Region of Ethiopia. North Shoa Zone is bordered on the south and the west by Oromia Region, on the north by South Wollo Zone, on the northeast by Oromia Zone and on the east by Afar Region. This zone is equipped with 10 public hospitals and 97 health centres, and on average 3200 mothers give birth at these health facilities, of whom 1200 deliver at public hospitals per month. The study was conducted at five public hospitals of North Shoa Zone: Debre Berhan Referral Hospital, Alem Ketema Enat Hospital, Ataye Hospital, Debre Sina Hospital and Shoa Robit Hospital. Delivery and FP services are provided free of charge at all public hospitals. Postpartum women who give birth via spontaneous vaginal delivery and caesarean section are discharged after 24 hours and 3-5 days of birth, respectively.

\section{Study population}

The study population included all postpartum women who gave birth (via vaginal or caesarean section) at the selected public hospitals of North Shoa Zone and fulfil the inclusion criteria.

\section{Eligibility criteria}

- Inclusion criteria: all postpartum women within 48 hours of delivery before discharge from the health facility and who were eligible for at least one IPPFP method according to 2015 MEC.

- Exclusion criteria: postpartum women who were critically ill and developed emergency cases and were prepared for referral to other health facilities.

\section{Sample size determination and sampling technique}

The sample size was determined using single population proportion formula considering the following assumptions: the proportion of women who used longacting reversible contraceptives among immediate postpartum mothers was $53.2 \%(\mathrm{p}=0.532)$, taken from a study conducted in Jimma Medical Center, with 95\% CI at 1.96 and with margin of error of $5 \% .^{5}$ 


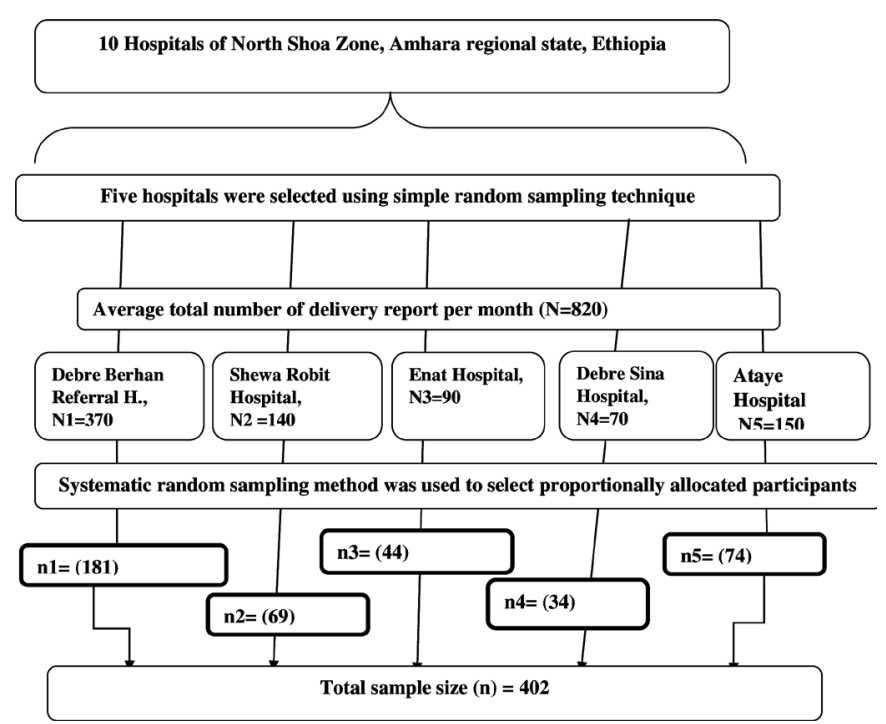

Figure 1 Schematic presentation of the sampling procedure to assess utilisation of immediate postpartum family planning among postpartum women at public hospitals of North Shoa Zone, Ethiopia, 2020.

$$
\mathrm{n}=\frac{(\mathrm{Z} \alpha / 2)^{2} \mathrm{p}(1-\mathrm{p})}{\mathrm{d}^{2}}
$$

After adding a $5 \%$ non-response rate, the final sample size was 402.

The calculated sample size was proportionally allocated to each public hospital based on the average number of institutional deliveries per month after observing two quarterly institutional delivery reports at the selected hospitals. A systematic random sampling technique was used to select an allocated sample of postpartum women from each selected public hospital. The calculated sampling interval $(\mathrm{K}=\mathrm{N} / \mathrm{n})$ was 2 . Therefore, the first woman was selected using a simple random sampling method and consecutive women were selected at a regular interval of the second postpartum women from the list of delivery registration books at selected public hospitals until the required sample size was obtained (figure 1).

\section{Data collection and data quality control}

Data were collected through face-to-face interviews at selected public hospitals using a structured and pretested questionnaire. The questionnaire was first prepared in English, then translated into the local language (Amharic) for data collection and back to English to ensure clarity and consistency during translation. To ensure clarity, to confirm the logical sequence and to check the reliability of the questionnaire, a pretest was done on $5 \%$ (20) of the total sample size at Deneba Primary Hospital. Necessary corrections were made based on the pretest results, and the Cronbach's alpha values for questions on knowledge, attitude and satisfaction with intrapartum care were 0.76 , 0.75 and 0.83 , respectively. When the providers decided to discharge the women, an exit interview was conducted for 20-25 min to collect data from each participant.

Five midwives who were diploma holders and three who were Bachelor of Science holders were involved in data collection and supervision, respectively. Data collectors and supervisors were trained for 1 day on the study's objective, eligibility criteria, data collection processes and ethical issues. In addition, all filled questionnaires were supervised daily for completeness and consistency.

\section{Study variables \\ Dependent variable}

- IPPFP utilisation.

\section{Independent variables}

- Sociodemographic characteristics: age, residence, marital status, women's educational status, husband's educational status, women's occupational status and family monthly income.

- FP-related characteristics: ever heard about IPPFP, source of information, ever counselled on IPPFP, counselled during ANC and PNC, ever used FP, discussion with husband, partner support to use FP, knowledge on FP and attitude towards FP.

- Obstetric and maternal health service-related characteristics: number of pregnancies, number of children alive, history of abortion, mode of delivery, current birth outcome, planning status of pregnancy, reproductive intention, plan when to have the next child, history of ANC for current pregnancy, number of ANC visits and maternal satisfaction with intrapartum care.

\section{Operational definitions and measurements of the study Utilisation of IPPFP}

Utilisation of IPPFP was defined as a postpartum woman using any one of modern postpartum FP methods (progesterone-only pills, intrauterine contraceptive device, injectables, dual method, sterilisation (permanent FP method) or implants) immediately within 48 hours of delivery before being discharged from the health facility. 527

\section{Knowledge of FP}

Knowledge of FP was measured using 17 questions, with participants asked to answer either 'yes' or 'no'. A value of 1 or 0 was given for each 'correct' or 'incorrect' response, respectively. The total score ranged from 0 to 17 and the mean was used as a cut-off point, which was adopted from the study conducted in Aroressa. ${ }^{28}$ The calculated total mean score for this study was 8 . Women who scored $\geq 8$ were categorised as having good knowledge and those who scored $<8$ were classified as having poor knowledge.

\section{Attitude towards FP}

Attitude towards FP was measured using 14 attitudinal questions. Participants were asked to rate their level of agreement towards FP using a 5-point Likert scale of 1 (strongly disagree) to 5 (strongly agree). The total score ranged from 14 to 60 and the mean was used as a cut-off point, which was adopted from the study conducted in Aroressa. ${ }^{28}$ The calculated total mean score for this study was 51 . Women who scored $\geq 51$ were considered to have a 
positive attitude and those who scored $<51$ were supposed to have a negative attitude towards FP.

\section{Maternal satisfaction with intrapartum care}

Maternal satisfaction was measured using 14 items. Participants were asked to rate their level of satisfaction using a 5-point Likert scale of 1 (strongly disagree) to 5 (strongly agree). The total score ranged from 14 to 60 and the cut-off score was calculated using the total mean score plus $1 \mathrm{SD}$, which was adopted from the Jordanian study. ${ }^{29}$ The total mean satisfaction score was 60 (overall mean 55.06 and SD 4.94). Women who scored $\geq 60$ and $<60$ were considered to be satisfied and dissatisfied with intrapartum care, respectively.

\section{Planning status of pregnancy}

Planning status of pregnancy indicates a woman's reproductive intention before she became pregnant, that is, whether the pregnancy was planned or unplanned.

\section{Dual method use}

Dual method use means using condoms plus other FP methods. ${ }^{30}$

\section{Statistical analysis}

Data were entered using EpiData V.4.6 and then exported to SPSS V.25 for further analysis. Descriptive analysis was summarised using proportion, mean and SD. Bivariate and multivariable logistic regression analysis methods were employed. In the univariate analysis, variables with $\mathrm{p}<0.25$ were candidates for multivariable logistic regression analysis. Multicollinearity among variables was checked using variance inflation factor (VIF $>10$ ). The VIF value of each explanatory variable was less than 2.7 $(\mathrm{VIF}<10)$; no multicollinearity was found within variables. The goodness of fit of the model was also checked using the Hosmer-Lemeshow goodness of fit test $(p=0.29)$. Statistical significance was declared at $\mathrm{p}<0.05$, along with adjusted OR (AOR) and 95\% CI.

Informed written consent was obtained from each study participant after explaining the study's objective. The information obtained from the participants was kept confidential.

\section{Patient and public involvement}

Neither the public nor the patients were involved in the design or conduct of this study. Participants also had no contribution to the writing or editing of this manuscript. However, informed written consent was taken from each participant before the interview.

\section{RESULTS}

\section{Socioeconomic and demographic characteristics}

Three hundred and ninety-four postpartum women participated in the study, resulting in a response rate of $98 \%$. The mean age of the participants was 29.08 years ( $\mathrm{SD} \pm 4.28)$, and majority $(172,43.7 \%)$ were between the age of 25 and 29 years. Majority $(359,91.1 \%)$ of the study participants were married, 293 (74.4\%) were Orthodox Christians and 284 (72.1\%) were of Amhara ethnicity. Of the study participants, $141(35.8 \%)$ were housewives, and $156(39.6 \%)$ women and $125(34.8 \%)$ of their partners had attended primary school (table 1 ).

\section{Obstetric and maternal health service-related characteristics}

Among the study participants, the mean number of pregnancies and living children was $2.46(\mathrm{SD} \pm 1.43)$ and 2.25 $(\mathrm{SD} \pm 1.3)$ per woman, respectively. The current pregnancy of majority $(287,72.8 \%)$ of the participants was planned, $319(81 \%)$ gave birth vaginally and $239(60.65 \%)$ wanted to delay having the next child in the future. Furthermore, majority $(200,50.3 \%)$ of the study participants had $\geq 4$ focused ANC visits during the current pregnancy. With regard to maternal satisfaction, $111(28.2 \%)$ respondents were satisfied with intrapartum care (table 2).

\section{FP-related characteristics}

Of the study participants, $190(48.2 \%)$ had ever heard about IPPFP and for $149(78.4 \%)$ of them health facilities were the primary source of information. Of the women, 163 (41.4\%) have received counselling on IPPFP, of whom $70(42.9 \%)$ received counselling integrated with both ANC and PNC services. Majority (302, 84.1\%) of the participants discussed FP with their husband and $179(59.3 \%)$ had partner support to use FP. Accordingly, $211(53.6 \%)$ and $181(45.9 \%)$ postpartum women had good knowledge of FP and a positive attitude towards FP, respectively (table 3 ).

\section{Utilisation of IPPFP}

Of the 394 participants, 84 (21.3\%) used IPPFP before discharge from the health facilities (figure 2), of which implant $(68,81 \%)$ was the most widely used IPPFP method, followed by PPIUCD $(11,13.1 \%)$ and dual method (5, 6.0\%).

Postpartum abstinence $(231,74.5 \%)$, lack of awareness $(165,53.2 \%)$, fear of side effects $(102,32.9 \%)$ and husband prohibition $(102,32.9 \%)$ are the major reasons stated by the participants for not currently using IPPFP (figure 3).

\section{Factors associated with IPPFP utilisation}

In the multivariable logistic regression analysis, maternal age (30-34), planning status of pregnancy, reproductive intention, partner support to use FP, attitude towards FP and maternal satisfaction with intrapartum care were statistically significantly associated with utilisation of IPPFP.

Women aged $30-34$ years were $88 \%$ less likely to use IPPFP than women aged $\geq 35$ years (AOR: $0.118 ; 95 \%$ CI 0.023 to 0.616 ). Mothers who reported their current pregnancy was planned were three times more likely to use IPPFP than mothers whose current pregnancy was unplanned (AOR: 3.175; 95\% CI 1.063 to 9.484). Postpartum women who were undecided about having the next child were five times more likely to use IPPFP than mothers who had a plan to have the next child (AOR: 
Table 1 Sociodemographic characteristics of postpartum women at public hospitals of North Shoa Zone, Ethiopia (N=394)

\begin{tabular}{|c|c|c|c|}
\hline Characteristics & Category & Frequency (n) & $\%$ \\
\hline \multirow[t]{3}{*}{ Age (in years) } & $\leq 24$ & 51 & 12.9 \\
\hline & $25-29$ & 172 & 43.7 \\
\hline & $\geq 35$ & 53 & 13.5 \\
\hline Residence & Urban & 196 & 49.7 \\
\hline & Muslim & 59 & 15 \\
\hline & Protestant & 36 & 9.1 \\
\hline & Catholic & 6 & 1.5 \\
\hline Current marital status & Married & 359 & 91.1 \\
\hline & Tigray & 21 & 5.3 \\
\hline & Others ${ }^{*}$ & 16 & 4.1 \\
\hline \multirow[t]{4}{*}{ Educational status of women } & No formal education & 60 & 15.2 \\
\hline & Primary & 156 & 39.6 \\
\hline & Secondary & 122 & 31.0 \\
\hline & College and above & 56 & 14.2 \\
\hline \multirow[t]{3}{*}{ Occupational status of women } & Daily labourer & 25 & 6.35 \\
\hline & Student & 25 & 6.35 \\
\hline & Employee & 64 & 16.2 \\
\hline & College and above & 101 & 28.1 \\
\hline \multirow[t]{4}{*}{ Family monthly income (in US\$) } & $\leq 44.3$ & 123 & 31.2 \\
\hline & $44.32-66.45$ & 129 & 32.7 \\
\hline & $66.47-88.6$ & 59 & 15.0 \\
\hline & $\geq 88.62$ & 83 & 21.1 \\
\hline
\end{tabular}

${ }^{*}$ Gurage and Argoba.

5.046; $95 \%$ CI 1.545 to 16.479$)$. The odds of using IPPFP were almost four times more likely among postpartum women who had partner support to use FP than women who had no partner support (AOR: 4.293; 95\% CI 1.181 to 15.61 ). Women who had a positive attitude towards FP were almost three times more likely to use IPPFP than their counterparts (AOR: 2.908; 95\% CI 1.081 to 7.824). Similarly, the likelihood of using IPPFP was 6.2 times higher among mothers who were satisfied with intrapartum care than mothers who were dissatisfied (AOR: 6.243; 95\% CI 2.166 to 17.994) (table 4).

\section{DISCUSSION}

For women who rarely contact the healthcare system, the provision of FP during the immediate postpartum period expands the opportunities for reaching couples with FP. This study mainly assessed the prevalence of IPPFP utilisation and the associated factors among postpartum women at public hospitals of North Shoa Zone, Ethiopia. Overall, the prevalence of IPPFP utilisation was $21.3 \%$ and factors such as maternal age, planning status of pregnancy, reproductive intention, partner support to use FP, attitude towards FP and satisfaction with intrapartum care were found to be significantly associated with utilisation. 
Table 2 Obstetrics and maternal health service-related characteristics of postpartum women at public hospitals of North Shoa Zone, Ethiopia ( $\mathrm{N}=394)$

\begin{tabular}{|c|c|c|c|}
\hline Characteristics & Category & Frequency (n) & $\%$ \\
\hline \multirow[t]{2}{*}{ Number of pregnancy } & $<2$ & 106 & 26.9 \\
\hline & $\geq 2$ & 288 & 73.1 \\
\hline \multirow{2}{*}{$\begin{array}{l}\text { History of abortion } \\
(n=288)\end{array}$} & No & 232 & 80.6 \\
\hline & Yes & 56 & 19.4 \\
\hline \multirow{3}{*}{$\begin{array}{l}\text { Birth to birth interval (in } \\
\text { months) }\end{array}$} & $<24$ & 110 & 39.1 \\
\hline & $24-35$ & 106 & 37.7 \\
\hline & $\geq 36$ & 65 & 23.1 \\
\hline \multirow{3}{*}{$\begin{array}{l}\text { Number of children } \\
\text { alive }\end{array}$} & 1 & 124 & 31.5 \\
\hline & $2-4$ & 242 & 61.4 \\
\hline & $\geq 5$ & 28 & 7.1 \\
\hline \multirow{2}{*}{$\begin{array}{l}\text { Planning status of } \\
\text { pregnancy }\end{array}$} & Unplanned & 107 & 27.2 \\
\hline & Planned & 287 & 72.8 \\
\hline \multirow{2}{*}{$\begin{array}{l}\text { History of ANC for } \\
\text { current pregnancy }\end{array}$} & No & 25 & 6.3 \\
\hline & Yes & 369 & 93.7 \\
\hline \multirow[t]{3}{*}{ Number of ANC visits } & Never visit & 25 & 6.3 \\
\hline & $<4$ & 169 & 42.9 \\
\hline & $\geq 4$ & 200 & 50.8 \\
\hline \multirow[t]{2}{*}{ Mode of delivery } & Vaginally & 319 & 81.0 \\
\hline & $\begin{array}{l}\text { Caesarean } \\
\text { section }\end{array}$ & 75 & 19.0 \\
\hline \multirow[t]{2}{*}{ Current birth outcome } & Alive & 360 & 91.4 \\
\hline & Dead & 34 & 8.6 \\
\hline \multirow[t]{3}{*}{ Reproductive intention } & $\begin{array}{l}\text { Want to } \\
\text { delay }\end{array}$ & 239 & 60.65 \\
\hline & Want to limit & 42 & 10.65 \\
\hline & Undecided & 113 & 28.7 \\
\hline \multirow{2}{*}{$\begin{array}{l}\text { Plan on when to have } \\
\text { the next child ( } \mathrm{n}=239) \\
\text { (in months) }\end{array}$} & $<24$ & 39 & 16.3 \\
\hline & $\geq 24$ & 200 & 83.7 \\
\hline \multirow{2}{*}{$\begin{array}{l}\text { Maternal satisfaction } \\
\text { with intrapartum care }\end{array}$} & Dissatisfied & 283 & 71.8 \\
\hline & Satisfied & 111 & 28.2 \\
\hline
\end{tabular}

ANC, antenatal care.

This study revealed that $21.3 \%$ (95\% CI 17.8 to 25.1 ) of postpartum women used IPPFP, consistent with studies done in Ethiopia $(19.1 \%-21.6 \%){ }^{31-33}$ However, the current finding was lower than the studies conducted in Georgia (49\%), ${ }^{34}$ Kenya $(50.3 \%),{ }^{35}$ Jimma $(53.2 \%)^{5}$ and Addis Ababa (45.5\%), ${ }^{36}$ and higher than the studies conducted in Pakistan $(4 \%)^{37}$ and Ethiopia $(12.7 \%-$ $13.6 \%) .{ }^{38}$ These variations might possibly be due to differences in sociocultural and demographic characteristics, study setting, data collection period and inclusion criteria. For instance, the inclusion criteria for the studies done in Jimma and Addis Ababa were postpartum women who received counselling on IPPFP within 48 hours and
Table 3 Family planning-related characteristics of postpartum women at public hospitals of North Shoa Zone, Ethiopia ( $\mathrm{N}=394)$

\begin{tabular}{llrl}
\hline Characteristics & Category & Frequency $(\mathbf{n})$ & $\%$ \\
\hline Ever heard about IPPFP & No & 204 & 51.8 \\
& Yes & 190 & 48.2 \\
\hline Source of information on & Health facility & 149 & 78.4 \\
IPPFP (n=190) & Mass media & 32 & 16.8 \\
& Others & 9 & 4.8 \\
\hline Ever counselled on IPPFP & No & 231 & 58.6 \\
in the current pregnancy & Yes & 163 & 41.4 \\
\hline Counselled on IPPFP & No & 93 & 57.1 \\
during ANC and PNC & Yes & 70 & 42.9 \\
(n=163) & No & 108 & 27.4 \\
Ever used FP method & Yes & 286 & 72.6 \\
\hline Discussion with husband & No & 57 & 15.9 \\
about FP (n=359) & Yes & 302 & 84.1 \\
\hline Support from husband & No & 123 & 40.7 \\
(n=302) & Yes & 179 & 59.3 \\
\hline Knowledge on FP & Poor knowledge & 183 & 46.4 \\
& Good knowledge & 211 & 53.6 \\
\hline Attitude towards FP & Negative attitude & 213 & 54.1 \\
& Positive attitude & 181 & 45.9 \\
\hline
\end{tabular}

*Friends and relatives.

ANC, antenatal care; FP, family planning; IPPFP, immediate postpartum family planning; PNC, postnatal care.

women who gave birth at the health facility within 7 days, respectively.

This finding also confirmed that postpartum abstinence, lack of awareness, fear of side effects and husband prohibition were barriers to using IPPFP as stated by the participants. Postpartum abstinence was the major reason stated by $231(74.5 \%)$ respondents for not using IPPFP. This finding was consistent with the studies conducted in Liberia ${ }^{40}$ and Addis Ababa, Ethiopia. ${ }^{36}$ The possible reason might be due to the religious perspectives of participants; postpartum women who were Orthodox Christians are usually separated from their husband and

Utilization of immediate postpartum family planning

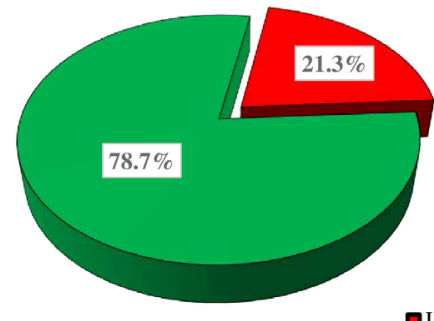

Utilized $\boldsymbol{\square}$ Not utilized

Figure 2 Immediate postpartum family planning utilisation among postpartum women at public hospitals of North Shoa, Ethiopia ( $\mathrm{N}=394)$. 


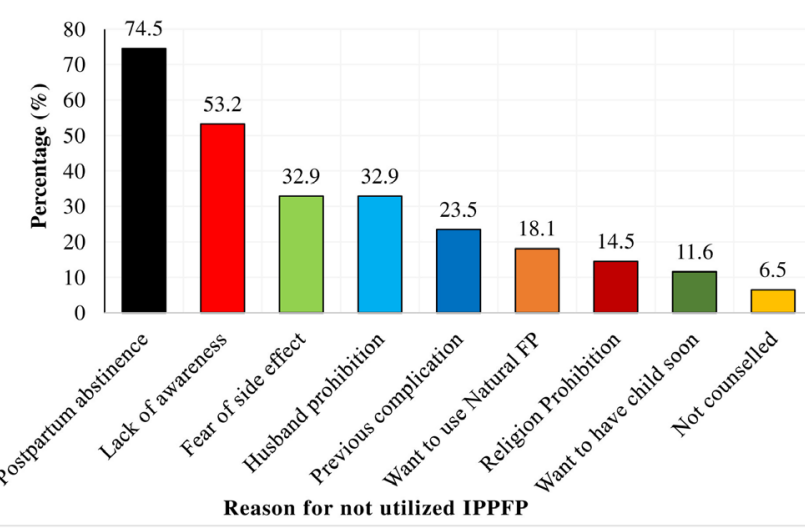

Figure 3 Reasons for not using IPPFP among postpartum women at public hospitals of North Shoa, Ethiopia $(n=310)$. FP, family planning; IPPFP, immediate postpartum family planning.

are sexually inactive until a priest blesses their child with holy water at 40 days and 80 days of birth of male and female infants, respectively. ${ }^{41}$

Women's age had a significant impact on IPPFP utilisation. Women aged $30-34$ years were $88 \%$ less likely to use IPPFP than women aged 35 years and above. This is supported by the study conducted in Malawi; the use of postpartum FP increased as maternal age and parity increased.$^{42}$ However, studies done in Gondar and Debre Tabor revealed that women aged $<24$ years and 25-29 years were more likely to use postpartum FP than women who were 35 years and above respectively. ${ }^{43}{ }^{44}$ A possible reason for the discrepancy could be the differences in sample size and study design. Also, women may have realised that getting pregnant when they become older can be difficult, encouraging them to plan for their next child sooner, which potentially has led to low FP utilisation. Moreover, women in younger and older age groups were more likely to be exposed to FP information and to achieve their desired number of children, respectively, which led them to use FP methods.

The odds of using IPPFP were higher among women who reported their current pregnancy was planned compared with mothers with unplanned pregnancy. This could be due to the healthcare-seeking status of the participants. Women who had unplanned pregnancy were found to less likely initiate and seek ANC early than women with planned pregnancy, ${ }^{45} 46$ and as a result these women are less likely to be exposed to and receive postpartum FP-related information.

Postpartum women who were undecided about having the next child in the future were more likely to use IPPFP than mothers who had a plan to have another child in the future. However, this finding contradicts the study conducted in Sidama Zone; mothers who were undecided about having another child were less likely to use postpartum intrauterine device (PPIUD) than mothers who had a plan to have another child. ${ }^{31}$ The possible reason for the discrepancy might be the difference in the FP options included in the study. The availability of a wide range of FP options at health facilities allows women to choose and use an FP method that best suits their needs. ${ }^{47}$ The time when the studies were conducted might also contribute to the variation; strategies to create FP-related community awareness improved from time to time.

Postpartum women who had partner support to use FP were more likely to use IPPFP than women who had no partner support. A similar finding was also reported by the study conducted in Addis Ababa, Ethiopia; IPPFP uptake improved by partner support. ${ }^{36}$ Studies done in Kenya and Gondar also showed that husband approval for contraceptive use was a significant factor for postpartum FP utilisation. ${ }^{35} 48$ This suggests that male involvement has a significant role in the use of reproductive and maternal health services. ${ }^{36} 49$

Mothers with a positive attitude towards FP were more likely to use IPPFP than their counterparts. This finding is in agreement with the study conducted in Kebribeyah; postpartum women who had a favourable attitude towards postpartum FP were more likely to use postpartum contraceptives than their counterparts. ${ }^{50}$ This could be due to attitude towards certain activity being an essential factor for the actual implementation of something being done in real situations. ${ }^{51}$ Furthermore, maternal satisfaction with intrapartum care was significantly associated with IPPFP utilisation. Satisfied women were more likely to use IPPFP than mothers who were dissatisfied with intrapartum care. This could be because women who were satisfied with the healthcare services they have received were more likely to enhance health-seeking behaviour and adhere to healthcare providers' counselling and recommendations, resulting in increased subsequent service utilisation. ${ }^{52} 53$

\section{Limitations of the study}

The findings of this study could help and serve as input for local programmers, policymakers, healthcare providers and other interested bodies looking to assess the implementation, barriers and utilisation of IPPFP. However, due to the cross-sectional nature of the study, the cause and effect relationship was not shown. Similarly, because this study was limited to public hospitals, the findings may not be generalisable to other settings. Potential response bias due to social desirability and the dichotomisation done for variables using Likert scale, such as attitude and satisfaction measurement items, were other limitations of this study. The findings of this study should be interpreted while considering these limitations.

\section{CONCLUSION AND RECOMMENDATION}

According to the findings of this study, only less than a quarter of postpartum women used IPPFP within 48 hours after giving birth before discharge from the hospital. Factors associated with utilisation of IPPFP were maternal age, planning status of pregnancy, partner support to use FP, reproductive intention, attitude towards FP and satisfaction with intrapartum care. Therefore, strengthening 
Table 4 Factors associated with IPPFP utilisation among postpartum women at public hospitals of North Shoa Zone, Ethiopia $(\mathrm{N}=394)$

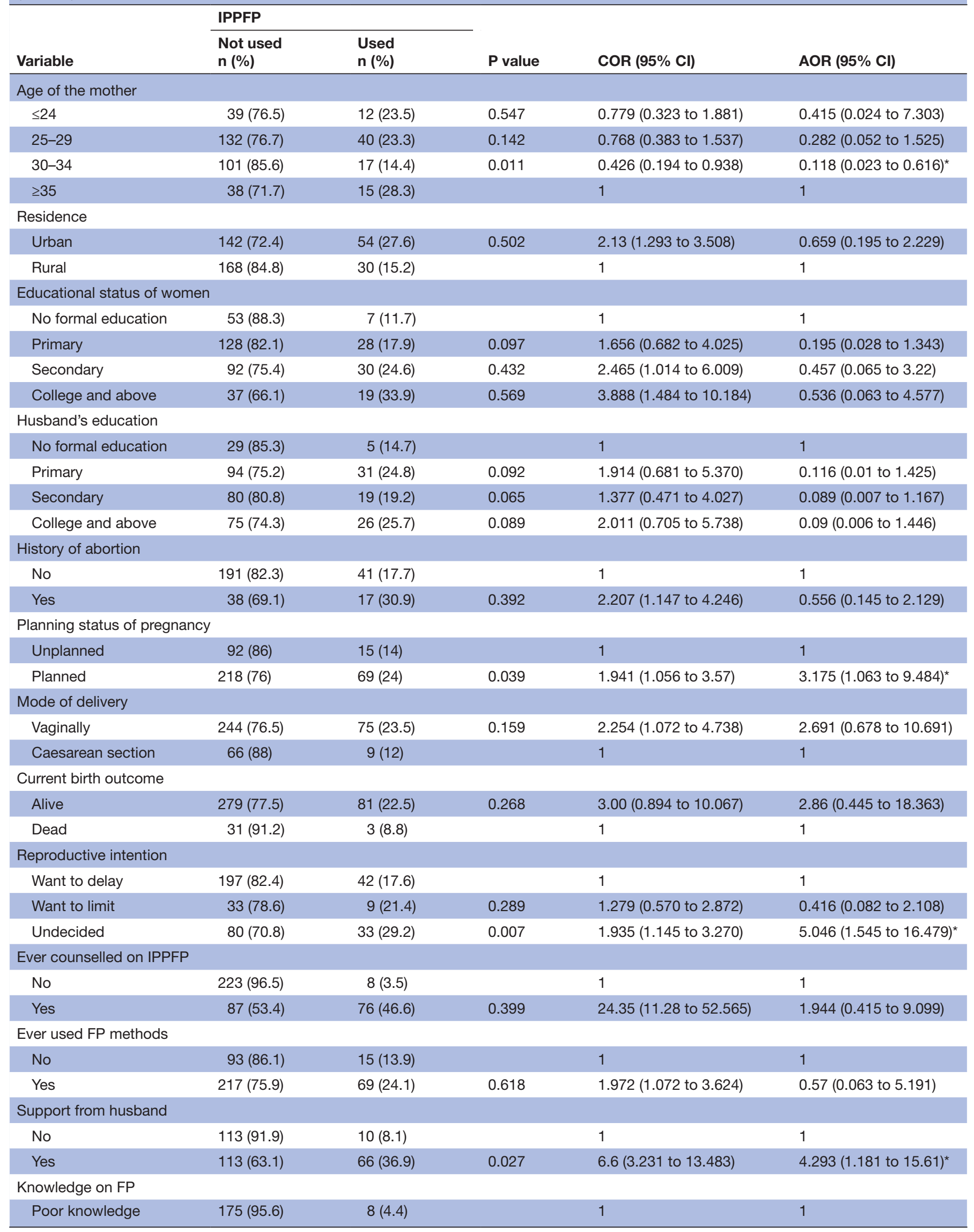


Table 4 Continued

\begin{tabular}{|c|c|c|c|c|c|}
\hline \multirow[b]{2}{*}{ Variable } & \multicolumn{2}{|l|}{ IPPFP } & \multirow[b]{2}{*}{$P$ value } & \multirow[b]{2}{*}{ COR (95\% Cl) } & \multirow[b]{2}{*}{ AOR $(95 \% \mathrm{Cl})$} \\
\hline & $\begin{array}{l}\text { Not used } \\
\text { n (\%) }\end{array}$ & $\begin{array}{l}\text { Used } \\
\text { n (\%) }\end{array}$ & & & \\
\hline \multicolumn{6}{|l|}{ Attitude towards FP } \\
\hline Negative attitude & $193(90.6)$ & $20(9.4)$ & & 1 & 1 \\
\hline Dissatisfied & 241 (85.2) & $42(14.8)$ & & 1 & 1 \\
\hline Satisfied & $69(62.2)$ & $42(37.8)$ & 0.001 & 3.493 (2.109 to 5.785$)$ & $6.243(2.166 \text { to } 17.994)^{*}$ \\
\hline
\end{tabular}

$1=$ reference category.

*Variables statistically significant at $\mathrm{p}<0.05$.

AOR, adjusted OR; COR, crude OR; FP, family planning; IPPFP, immediate postpartum family planning.

community awareness about FP to develop positive attitude towards FP, encouraging partner involvement in FP and ensuring maternal satisfaction are crucial to enhance the utilisation of IPPFP. Finally, the authors suggest a larger multicentre study that includes healthcare systemrelated and service provider-related factors.

\section{Twitter Samuel Abdu @SamuelAbdu2}

Contributors MS has been conceived and designed the study, carried out the statistical analysis, and writing and editing of the original draft. TL, SA and BTT has contributed in the data collection process, supervised the overall steps of the study and reviewed the final draft. BF and MT critically supervised, reviewed and revised the final draft paper. MS has accepted full responsibility for the work and/or the conduct of the study, had access to the data, and controlled the decision to publish. All authors made critical review, read, and approved the final manuscript.

Disclaimer The funder had no role in the design and conduct of the study, in the collection, analysis and interpretation of the data.

Competing interests None declared.

Patient and public involvement Patients and/or the public were not involved in the design, or conduct, or reporting, or dissemination plans of this research.

Patient consent for publication Not required.

Ethics approval This study involves human participants and was approved by the Jimma University Institutional Review Board (ref no: IRB000164/20). Formal permission letters were also received from the administration of the North Shoa Zone Health Bureau and the medical directors of each hospital. Participants gave informed consent to participate in the study before taking part.

Provenance and peer review Not commissioned; externally peer reviewed.

Data availability statement Data are available upon reasonable request.

Open access This is an open access article distributed in accordance with the Creative Commons Attribution Non Commercial (CC BY-NC 4.0) license, which permits others to distribute, remix, adapt, build upon this work non-commercially, and license their derivative works on different terms, provided the original work is properly cited, appropriate credit is given, any changes made indicated, and the use is non-commercial. See: http://creativecommons.org/licenses/by-nc/4.0/.

\section{ORCID iDs}

Mulualem Silesh http://orcid.org/0000-0002-1943-041X

Tesfanesh Lemma http://orcid.org/0000-0003-3038-5821

Mesfin Tadese http://orcid.org/0000-0001-6288-9771

Birhan Tsegaw Taye http://orcid.org/0000-0003-2174-3797

\section{REFERENCES}

1 Guttmacher Institute, BMGF. Adding it up: investing in contraception and maternal and newborn health. Guttmacher Inst, 2017. http:// www.gatesfoundation.org/What-We-Do/Global-Development/FamilyPlanning\%0Ahttps://www.guttmacher.org/fact-sheet/adding-it-upcontraception-mnh-2017

2 Gaffield ME, Egan S, Temmerman M. It's about time: WHO and partners release programming strategies for postpartum family planning. Glob Health Sci Pract 2014;2:4-9.

3 WHO. Who programming strategies for postpartum family planning, 2013. Available: http://www.who.int/reproduc $\neg$ tivehealth/ publications/family_planning/ppfp_strategies/en/

4 Family planning high impact practices. High impact practices in family planning (hip), 2018. Available: https://www.fphighimpactprac tices.org/high-impact-practices-in-family-planning-list/

5 Arero W, Teka W, Jarso H. Prevalence, and Pattern of LARC Use in Immediate Postpartum Period at Jimma University Medical Center, Ethiopia [18F]. Obstet Gynecol 2018;131:68S.

6 Thompson EL, Vamos CA, Logan RG, et al. Patients and providers knowledge, attitudes, and beliefs regarding immediate postpartum long-acting reversible contraception: a systematic review. Women Health 2020;60:179-96.

7 Rankin KM, Kroelinger CD, DeSisto CL, et al. Application of implementation science methodology to immediate postpartum longacting reversible contraception policy roll-out across states. Matern Child Health J 2016;20:173-9.

8 World Health Organization. Medical eligibility criteria for contraceptive use. 3rd edn, 2004. https://apps.who.int/iris/handle/ 10665/181468

9 World Health Organization (WHO). Maternal mortality. Available: https://www.cdc.gov/reproductivehealth/maternal-mortality/index. html

10 Tran NT, Gaffield ME, Seuc A, et al. Effectiveness of a package of postpartum family planning interventions on the uptake of contraceptive methods until twelve months postpartum in Burkina Faso and the Democratic Republic of Congo: the yam DAABO study protocol. BMC Health Serv Res 2018;18:439.

11 Rutstein S, Winter R. Contraception needed to avoid High-FertilityRisk births and maternal and child deaths ThatWould be averted, 2014: 4-6. https://dhsprogram.com/pubs/pdf/AS50/AS50.pdf

12 Cleland J, Conde-Agudelo A, Peterson H, et al. Contraception and health. Lancet 2012;380:149-56.

13 IEEE. ICF CSA (CSA) [Ethiopia] and. 2016 Ethiopia Demographic and Health Survey Key Findings, 2017. Available: http://ieeexplore.ieee. org/document/1345625/

14 Practice B, No P. Best practice in postpartum family planning, 2015. Available: http://www.who.int/reproduc $\neg$ tivehealth/publications/ family_planning/ppfp_strategies/en/

15 Chethan R, G. S. A, C. S, Anitha GS, Savitha C. Study on post partum intrauterine contraceptive device practices and causes for discontinuation of PPIUCD at follow up in a tertiary hospital. Int $J$ Reprod Contracept Obstet Gynecol 2018;7:2299-303.

16 Glasier A, Baird D, Blumenthal P. Best practice paper in postpartum family planning. $R$ Coll Obstet Gynaecol 2015;1:1-13.

17 Bishwajit G, Tang S, Yaya S, et al. Unmet need for contraception and its association with unintended pregnancy in Bangladesh. BMC Pregnancy Childbirth 2017;17:1-9. 
18 Horvath S, Schreiber CA. Unintended pregnancy, induced abortion, and mental health. Curr Psychiatry Rep 2017;19:77. doi:10.1007/ s11920-017-0832-4

19 FMOH. Ethiopian Health Sector Transformation Plan.2015/16 2019/20. Vol 20, 2015. https://www.globalfinancingfacility.org/sites/ gff_new/files/Ethiopia-health-system-transformation-plan.pdf

20 Dagnew GW, Asresie MB, Fekadu GA, et al. Modern contraceptive use and factors associated with use among postpartum women in Ethiopia; further analysis of the 2016 Ethiopia demographic and health survey data. BMC Public Health 2020;20:1-9. doi:10.1186/ s12889-020-08802-6

21 Institute E public health, ICF. Mini demographic and health survey: key indictors, 2019: 136-48. www.DHSprogram.com

22 Zimmerman LA, Yi Y, Yihdego M, et al. Effect of integrating maternal health services and family planning services on postpartum family planning behavior in Ethiopia: results from a longitudinal survey. BMC Public Health 2019;19:1-9. doi:10.1186/s12889-019-7703-3

23 Track 20. Opportunities for family planning programming in the postpartum period in Ethiopia, 2020: 1-2.

24 Cleland J, Bernstein S, Ezeh A, et al. Family planning: the unfinished agenda. Lancet 2006;368:1810-27. doi:10.1016/S01406736(06)69480-4

25 Borda MR, Winfrey W, McKaig C. Return to sexual activity and modern family planning use in the extended postpartum period: an analysis of findings from seventeen countries. Afr $J$ Reprod Health 2010;14:72-9.

26 Rossier C, Hellen J. Traditional birthspacing practices and uptake of family planning during the postpartum period in Ouagadougou: qualitative results. Int Perspect Sex Reprod Health 2014;40:087-94. doi:10.1363/4008714

27 Abraha TH, Teferra AS, Gelagay AA. Postpartum modern contraceptive use in northern Ethiopia: prevalence and associated factors. Epidemiol Health 2017;39:e2017012.

28 Dona A, Abera M, Alemu T, et al. Timely initiation of postpartum contraceptive utilization and associated factors among women of child bearing age in Aroressa district, southern Ethiopia: a community based cross-sectional study. BMC Public Health 2018;18:1-9.

29 Khitam ISM, Insaf S, Caroline $\mathrm{H}$, et al. Womens satisfaction with hospital-based intrapartum care: a Jordanian study. Int. J. Nurs. Midwifery 2014;6:32-9. doi:10.5897/IJNM2014.0127

30 Quispe Calla NE, Vicetti Miguel RD, Trout W, et al. Hiv and hormonal contraception: bench and bedside. J Acquir Immune Defic Syndr 2017;74:e85-6. doi:10.1097/QAI.0000000000001174

31 Tefera LB, Abera M, Fikru C, et al. Utilization of immediate postpartum intra uterine contraceptive device and associated factors: a facility based cross sectional study among mothers delivered at public health facilities of Sidama zone, South Ethiopia. J Pregnancy Child Health 2017;04:1-8. doi:10.4172/2376-127X.1000326

32 Ejigu Tafere T, Afework MF, Yalew AW. Antenatal care service quality increases the odds of utilizing institutional delivery in Bahir Dar City administration, North Western Ethiopia: a prospective follow up study. PLoS One 2018;13:1-9.

33 PATHFINDER. Expanding Contraceptive Options for Postpartum Women in Ethiopia : Introducing the Postpartum IUD: When can a copper-bearing IUD be inserted ? Postpartum, 2016: 1-7. https:// www.pathfinder.org/publications/expanding-contraceptive-optionsfor-postpartum-women-in-ethiopia/

34 DeSisto CL, Handler A, Haider S, et al. Women's informed choice and satisfaction with immediate postpartum long-acting reversible contraception in Georgia. Contracept Reprod Med 2018;3:1-10. doi:10.1186/s40834-018-0073-x

35 Shabiby MM, Karanja JG, Odawa F, et al. Factors influencing uptake of contraceptive implants in the immediate postpartum period among HIV infected and uninfected women at two Kenyan district hospitals. BMC Womens Health 2015;15:62. doi:10.1186/s12905-015-0222-1

36 Belay L, Birara M. Factors affecting long-term and permanent contraceptive uptake among immediate post-partum mothers at Saint Paul' S Hospital millennium medical. Ethiop J Reprod Heal 2018;10:31-41.
37 Abbasi Y, Shaikh SR, Memon KN. Barriers and missed opportunities towards immediate and early post-partum family planning methods in Pakistan. The Professional Medical Journal 2020;27:1448-53. doi:10.29309/TPMJ/2020.27.07.4273

38 Gejo NG, Anshebo AA, Dinsa LH. Postpartum modern contraceptive use and associated factors in Hossana town. PLoS One 2019:14:1-10.

39 Jima GH, Garbaba WB. Postpartum family planning utilization and associated factors among women who gave birth in the last 12 months prior to the study in lode Hetosa district, South East Ethiopia. $J$ Women's Heal Care 2020;9:1-11 https://www.longdom.org/openaccess/postpartum-family-planning-utilization-and-associatedfactors-among-women-who-gave-birth-in-the-last-12-months-priorto-the-study--53955.html

40 Kaydor VK, Adeoye IA, Olowolafe TA, et al. Barriers to acceptance of post-partum family planning among women in Montserrado County, Liberia. Niger Postgrad Med J 2018;25:143-8.

41 Molakign A. Ethiopian EthnoMed, 2008. Available: https://ethnomed. org/culture/ethiopian/

42 Bwazi C, Maluwa A, Chimwaza A, et al. Utilization of postpartum family planning services between six and twelve months of delivery at Ntchisi district Hospital, Malawi. Health 2014;06:1724-37. doi:10.4236/health.2014.614205

43 Taye EB, Mekonen DG, Debele TZ. Prevalence of post partum modern family planning utilization and associated factors among postpartum mothers in Debre Tabor town, North West Ethiopia, 2018. BMC Res Notes 2019;12:430. doi:10.1186/s13104-019-4464-0

44 Abera Y, Mengesha ZB, Tessema GA. Postpartum contraceptive use in Gondar town, Northwest Ethiopia: a community based crosssectional study. BMC Womens Health 2015;15:1-8. doi:10.1186/ s12905-015-0178-1

45 Abame DE, Abera M, Tesfay A, et al. Relationship between unintended pregnancy and antenatal care use during pregnancy in Hadiya zone, southern Ethiopia. J Reprod Infertil 2019;20:42-51.

46 Wado YD, Afework MF, Hindin MJ. Unintended pregnancies and the use of maternal health services in southwestern Ethiopia. BMC Int Health Hum Rights 2013;13:1. doi:10.1186/1472-698X-13-36

47 Wang W, Mallick L. Understanding the relationship between family planning method choices and modern contraceptive use: an analysis of geographically linked population and health facilities data in Haiti. BMJ Glob Heal 2020;4:1-10. doi:10.1136/bmjgh-2018-000765

48 Berta M, Feleke A, Abate T, et al. Utilization and associated factors of modern contraceptives during extended postpartum period among women who gave birth in the last 12 months in Gondar town, Northwest Ethiopia. Ethiop J Health Sci 2018;28:207. doi:10.4314/ ejhs.v28i2.12

49 Gizaw W, Yang L, Zewdu F. Extended postpartum modern contraceptive utilization and associated factors among women in Gozamen district, East Gojam zone, Northwest Ethiopia. iMedPub Journals 2017:1:1-6.

50 AT N, D G, G T. Postpartum family planning utilization and associated factors among women who gave birth in the past 12 months, Kebribeyah town, Somali region, eastern Ethiopia. J Womens Health Care 2016;05. doi:10.4172/2167-0420.1000340

51 Semachew Kasa A, Tarekegn M, Embiale N, Knowledge EN. Knowledge, attitude and practice towards family planning among reproductive age women in a resource limited settings of northwest Ethiopia. BMC Res Notes 2018;11:577-12. doi:10.1186/s13104-0183689-7

52 Yohannes B, Tarekegn M, Paulos W. Mothers " utilization of antenata care and their satisfaction with delivery services in selected public health facilities of wolaita zone, Southern Ethiopia. Nternational J Sci Technol Res 2013;2:74-85 https://www.researchgate.net/publication/ 235743283 Mothers_Utilization_Of_Antenatal_Care_And_Their Satisfaction_With_Delivery_Services_In_Selected_Public_Health_ Facilities_Of_Wolaita_Zone_Southern_Ethiopia

53 Demas T, Getinet T, Bekele D, et al. Women's satisfaction with intrapartum care in ST Paul's Hospital millennium medical college Addis Ababa Ethiopia: a cross sectional study. BMC Pregnancy Childbirth 2017;17:253. doi:10.1186/s12884-017-1428-z 